\title{
Acro-cardio-facial syndrome
}

\author{
Maria Cristina Digilio*, Bruno Dallapiccola
}

\begin{abstract}
Acro-cardio-facial syndrome (ACFS) is a rare genetic disorder characterized by split-hand/split-foot malformation (SHFM), facial anomalies, cleft lip/palate, congenital heart defect (CHD), genital anomalies, and mental retardation. Up to now, 9 patients have been described, and most of the reported cases were not surviving the first days or months of age. The spectrum of defects occurring in ACFS is wide, and both interindividual variability and clinical differences among sibs have been reported. The diagnosis is based on clinical criteria, since the genetic mechanism underlying ACFS is still unknown. The differential diagnosis includes other disorders with ectrodactyly, and clefting conditions associated with genital anomalies and heart defects. An autosomal recessive pattern of inheritance has been suggested, based on parental consanguinity and disease's recurrence in sibs in some families. The more appropriate recurrence risk of transmitting the disease for the parents of an affected child seems to be up to one in four. Management of affected patients includes treatment of cardiac, respiratory, and feeding problems by neonatal pediatricians and other specialists. Prognosis of ACFS is poor.
\end{abstract}

\section{Disease name and synonyms}

Acro-cardio-facial syndrome (ACFS)

Cleft palate-cardiac defect-genital anomalies-ectrodactyly (CCGE) syndrome

\section{Definition}

Acro-cardio-facial syndrome (ACFS, OMIM 600460) is a rare genetic disorder characterized by split-hand/ split-foot malformation (SHFM), facial anomalies, cleft lip/palate, congenital heart defect (CHD), genital anomalies, and mental retardation. This association was first described by Richieri-Costa and Orquizas in 1987 in a Brazilian patient born to consanguineous parents [1]. The existence of this syndrome was corroborated by the report of 8 additional patients [2-7]. We are aware of an additional Turkish patient born to consanguineous parents (Kayresili, personal communication 2009), presenting with SHFM, aortic stenosis, cleft palate, hypoplastic corpus callosum, and atretic ears. The acronym CCGE (cleft palate-cardiac defectgenital anomalies-ectrodactyly) was also proposed to identify this unique constellation of anomalies [2]. Additional features occasionally found in these individuals include cortical atrophy of the brain [3], cerebral

\footnotetext{
* Correspondence: maria.digilio@opbg.net
Division of Medical Genetics, Bambino Gesù Pediatric Hospital, IRCCS, Piazza

* Correspondence: maria.digilio@opbg.net
Division of Medical Genetics, Bambino Gesù Pediatric Hospital, IRCCS, Piazza S. Onofrio 4, 00165, Rome, Italy
}

C 2010 Digilio and Dallapiccola; licensee BioMed Central Ltd. This is an Open Access article distributed under the terms of the Creative

\section{Epidemiology}

The incidence of ACFS has not been determined, due to the paucity of the reported cases, but it is likely a very rare disease $(<<1$ in 100,000 newborns). A similar occurrence among genders is expected for an autosomal disorder. The excess of male patients reported so far $(7 \mathrm{M}: 3 \mathrm{~F})$ is likely biased by the low number of observations.

\section{Clinical description}

Clinical features of ACFS are summarized in Table 1. The most important diagnostic handles are SHFM and CHD. The spectrum of defects occurring in ACFS is wide, and both interindividual variability and clinical differences among sibs have been documented. Most published cases have not survived the first days or months of life.

\section{Limbs}

Cleft hand is a constant feature, either bilateral or unilateral (figure 1C). Subluxation of metacarpophalangeal joints and finger flexion at the proximal interphalangeal 
Table 1 Major clinical features of the acro-cardio-facial syndrome

\begin{tabular}{|c|c|c|c|c|c|c|c|c|c|c|c|}
\hline \multirow[t]{2}{*}{ Clinical finding } & \multicolumn{8}{|c|}{ References } & & \multirow[t]{2}{*}{ Total \% } & \\
\hline & 1 & $2 a$ & $2 b$ & 3 & 4 & $5 a$ & $5 b$ & 6 & 7 & & \\
\hline Sex & $M$ & $M$ & $F$ & M & M & M & $\mathrm{F}$ & $F$ & $M$ & $6 \mathrm{M} / 3 \mathrm{~F}$ & \\
\hline Facial anomalies & + & + & + & + & + & + & + & + & + & $9 / 9$ & 100 \\
\hline High forehead & - & + & NK & - & + & + & + & NK & + & $5 / 7$ & 71 \\
\hline Prominent eyes & - & - & NK & + & + & - & - & NK & - & $2 / 7$ & 29 \\
\hline Long eyelashes & + & - & NK & + & + & - & - & NK & - & $3 / 7$ & 43 \\
\hline Hypertelorism & - & - & NK & + & + & + & + & NK & + & $5 / 7$ & 71 \\
\hline Broad/flat nasal root & + & + & NK & + & + & - & - & NK & + & $5 / 7$ & 71 \\
\hline Cleft lip & + & - & - & + & - & - & - & - & + & $3 / 9$ & 33 \\
\hline Cleft palate & + & - & + & + & - & - & NK & + & + & $5 / 8$ & 63 \\
\hline Low-set dysmorphic ears & + & + & NK & + & + & + & + & + & + & $8 / 8$ & 100 \\
\hline Limb anomalies & + & + & + & + & + & + & + & + & + & $9 / 9$ & 100 \\
\hline Cleft hand (bilateral) & + & + & + & + & - & + & + & + & - & $7 / 9$ & 78 \\
\hline Cleft hand (unilateral) & - & - & - & - & + & - & - & - & + & $2 / 9$ & 22 \\
\hline Cleft foot (bilateral) & + & - & - & - & - & - & + & - & - & $2 / 9$ & 22 \\
\hline Cleft foot (unilateral) & - & - & - & - & + & - & - & - & - & $1 / 9$ & 11 \\
\hline Congenital heart defect & + & + & - & + & + & - & - & + & + & $6 / 9$ & 67 \\
\hline Ventricular septal defect & + & + & - & - & - & - & - & + & - & $3 / 9$ & 33 \\
\hline Atrial septal defect & - & + & - & - & - & - & - & + & - & $2 / 9$ & 22 \\
\hline Aortic coarctation & - & + & - & + & - & - & - & - & - & $2 / 9$ & 22 \\
\hline Mitral atresia & - & + & - & - & - & - & - & - & - & $1 / 9$ & 11 \\
\hline Truncus arteriosus & - & - & - & - & + & - & - & - & - & $1 / 9$ & 11 \\
\hline Tetralogy of Fallot & - & - & - & - & - & - & - & - & + & $1 / 9$ & 11 \\
\hline Absent left pulmonary artery & - & - & - & - & - & - & - & - & + & $1 / 9$ & 11 \\
\hline Genital anomalies & + & + & NA & - & + & + & NA & NA & + & $5 / 6$ & 83 \\
\hline Micropenis & + & + & NA & - & - & + & NA & NA & + & $4 / 6$ & 67 \\
\hline Cryptorchidism & + & + & NA & - & + & + & NA & NA & - & $4 / 6$ & 67 \\
\hline Hypospadia & + & + & NA & - & - & + & NA & NA & - & $3 / 6$ & 50 \\
\hline Low birth weight $(<3$ rd centile) & - & + & + & - & - & + & + & - & + & $5 / 9$ & 56 \\
\hline Growth retardation & + & + & NA & + & + & - & NA & NK & + & $5 / 6$ & 83 \\
\hline Neurological anomalies & + & + & NK & + & + & - & NK & + & + & $6 / 7$ & 86 \\
\hline Mental retardation & + & + & NK & + & + & - & NK & NK & + & $5 / 6$ & 83 \\
\hline Hypotonia/Hypertonia & + & + & NK & - & + & - & NK & NK & - & $3 / 6$ & 50 \\
\hline Cortical brain atrophy & + & - & - & + & NK & NK & NK & - & NK & $2 / 5$ & 40 \\
\hline Neuropepithelial cyst & - & - & - & - & NK & NK & NK & + & NK & $1 / 5$ & 20 \\
\hline Dead/Alive & Alive & Dead & Dead & Dead & Dead & Alive & Dead & Dead & Dead & & \\
\hline Age & $4 y$ & $1 \mathrm{~m}$ & $6 \mathrm{~h}$ & $4 \mathrm{~m}$ & $1 \mathrm{~m}$ & $25 y$ & $4 d$ & $50 d$ & $14 y$ & & \\
\hline
\end{tabular}

References: 1, Richieri-Costa and Orquizas, 1987 [1]; 2, Giannotti et al., 1995 [2]; 3, Guion-Almeida et al., 2000 [3]; 4, Mingarelli et al., 2005 [4]; 5, Sivasli et al., 2007 [5]; 6, Kariminejad et al., 2008 [6]; 7, Tanpaiboon et al., 2009 [7].

Abbreviations: M, Male; F, female; NK, not known; NA, not applicable; y, years; m, months; h, hours; d, days.

joints can be also found [6]. Cleft foot occurs in a proportion of these patients. Cutaneous finger and toe syndactyly has been reported in some cases [3-5].

Radiographic findings include cleft hand/foot with agenesis of fingers [1-7] (figure 1E), abnormal structure and articulation of the first metacarpal bone [4,6,7], hypoplastic and short metacarpal bones [1-7], presence of extrabones between phalanges [6,7], hallux valgus [4], absent or abnormally modelled phalanges of toes [4], polydactyly of foot [5]. 

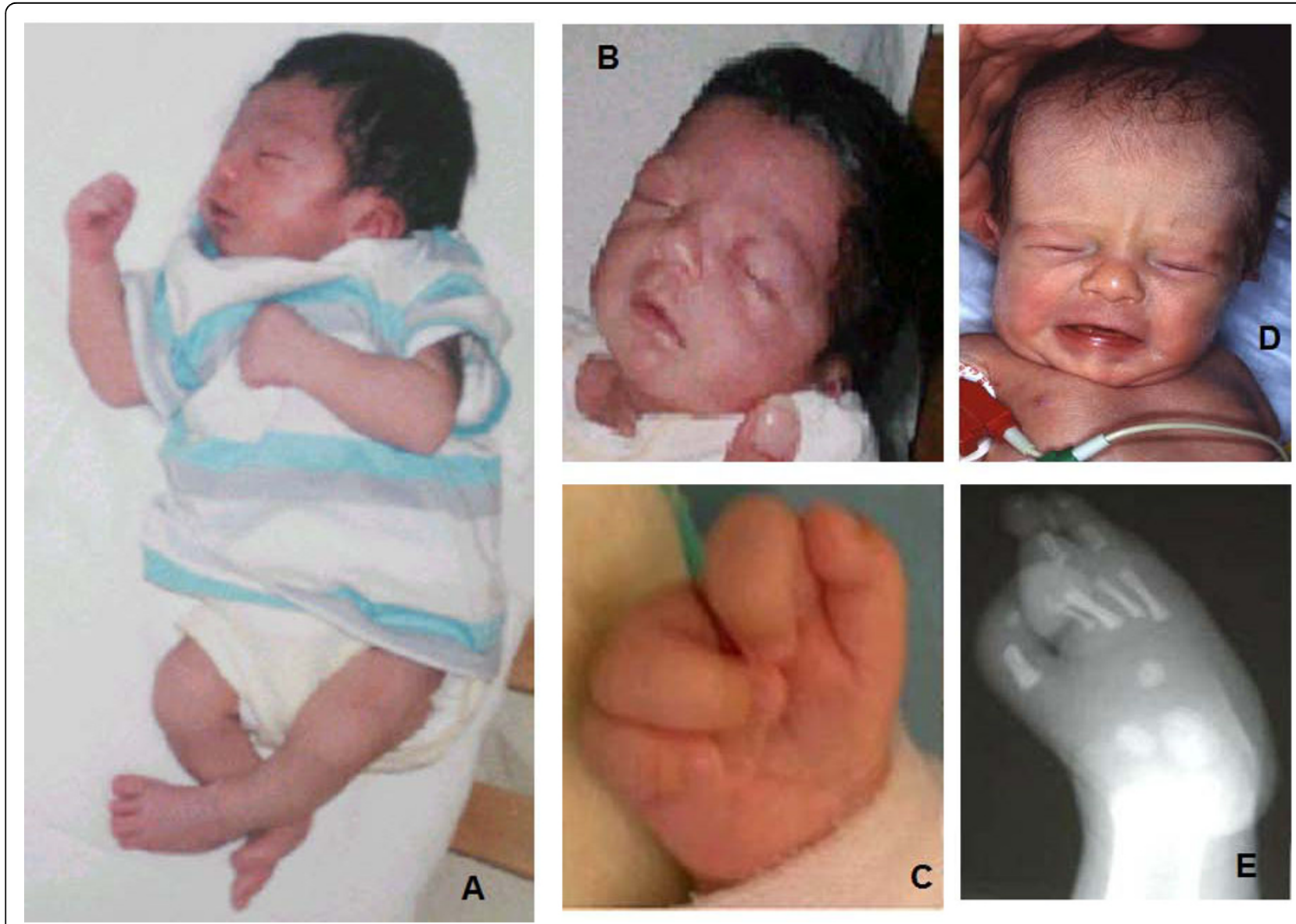

Figure $1 \mathrm{Facial}$ and limb features of two patients with the acro-cardio-facial syndrome: A, B, C, E: patient reported by Mingarelli et al., 2005 [4]; D: patient reported by Giannotti et al., 1995 [2](2a in Table 1). A: Lateral total body view; B: Facial appearance of patient 4,

showing high forehead, prominent eyes, long eyelashes, hypertelorism, broad nasal root; C: Ectrodactyly of right hand; D: Facial appearance of patient 2a, showing high forehead, broad nasal root, low-set dysmorphic ears; E: X-ray of right foot, showing split foot malformation with five metatarsal (including a very hypoplastic second metatarsal) and absence of all the phalanges of second and third toes.

\section{Congenital heart defects}

CHD have been detected in two third of the patients [1-5,7]. Anatomic types are heterogeneous, including septal defects [1,5], left-sided obstructive lesions [2,3], and conotruncal defects [4,7]. Left-sided obstructive lesions have been described, as aortic coarctation and hypoplastic left heart. Conotruncal heart defects include truncus arteriosus type 1 with dysplastic and stenotic truncal valves [4] and tetralogy of Fallot with absent left pulmonary artery [7].

\section{Facial anomalies}

Facial anomalies are not distinct for the syndrome, and clinical expression appears quite variable. Reported dysmorphisms include high forehead, prominent eyes, long eyelashes, hypertelorism, flat nasal root, low-set dysmorphic ears (figure 1A, B, D). Lip and palate anomalies are often present, manifesting as bilateral cleft lip and cleft palate [1,7], unilateral cleft lip and palate [3], cleft palate only $[2,5]$

\section{Genital anomalies}

Male patients manifest different genital anomalies, ranging from micropenis $[1,2,6,7]$ to cryptorchidism $[1,2,4,6]$, and hypospadia $[1,2,6]$.

\section{Growth}

Growth retardation is a common prenatal and postnatal finding, resulting in low birth weight $[2,6,7]$, weight deficiency often in conjunction with feeding difficulties $[1-3,7]$, and short stature [1,6,7].

\section{Neurological anomalies}

The prevalence of mental retardation in ACFS is at present unknown, due to early demise of the majority of these patients. One of the two survivors was mentally 
normal by age 25 years [6], while the other displayed developmental delay at the age of 4 years [1]. A patient described by Tanpaiboon et al [2009] [7], who died at age of 14 years, was mentally normal. Neurological anomalies as hypotonia, hypertonia, and seizures have been reported in the first days/months of life. Occasional brain anomalies have been observed, including cortical atrophy $[1,3]$ and cerebral neuroepithelial cyst [5].

\section{Etiology}

The genetic mechanism underlying ACFS is still unknown. Isolated or syndromic SHFM has been linked to different loci or genes. Mutations in p63 gene, responsible for Ectrodactyly-Ectodermal defects-Cleft (EEC) syndrome and related disorders with SHFM [8], have been excluded in a patient with ACFS [7]. An autosomal recessive pattern of inheritance is supported both by consanguinity in a few families and recurrence in sibs born to unaffected parents $[1,2,6]$. The involvement of a small chromosomal microdeletion cannot be ruled out, since CGHarray has never been performed in published patients. The possibility should also be considered that this condition could be genetically heterogeneous.

\section{Diagnosis}

The diagnosis of ACFS is solely based on clinical characteristics. The major diagnostic criteria include SHFM and CHD. Cleft lip/palate and genital anomalies are less common features. Although facial anomalies are not distinct, low-set dysmorphic ears appear as a constant feature. Recurrence among sibs born to unaffected parents suggests an autosomal recessive inheritance and provides a clue to differentiate ACFS from autosomal dominant disorders with similar features.

\section{Antenatal diagnosis}

The major diagnostic features characteristic of ACFS can be detected prenatally by ultrasonography. A second trimester scan, including echocardiography and upper/ lower limbs evaluation is recommended for monitoring the pregnancies of parents with an affected child.

\section{Genetic counselling}

An autosomal recessive pattern of inheritance has been established for ACFS. Therefore, the more appropriate recurrence risk of transmitting the disease for the parents of an affected child seems to be up to one in four.

\section{Differential diagnosis}

ACFS shares features with other ectrodactyly syndromes and clefting conditions associated with genital anomalies. However, EEC syndrome [9], Rapp-Hodgkin syndrome [10] and ectrodactyly-cleft lip/palate-hand/foot deformities-mental retardation [11,12] can be ruled out, based on lack of ectodermal involvement in ACFS. Malpuech syndrome can be also excluded based on distinct facial features and absent limb defects [13]. CHD, cleft palate, and genital anomalies are features of genitopalato-cardiac syndrome, but none of the reported cases had ectrodactyly [14]. DiGeorge/velo-cardio-facial syndrome can be considered in patients with conotruncal heart defect [4,7], and excluded using FISH analysis of chromosome 22q11.2 [4]. CHARGE syndrome can also be included among conditions in differential diagnosis, since SHFS can be found and ears can be similar in the two conditions [3].

\section{Management}

Patients with ACFS are at high risk of death in the first months of age. The co-occurrence of CHD, low birth weight and hypotonia probably play a major role onto the weakness of affected patients. Cardiac and respiratory problems should be treated by the neonatologist and other specialists, including the cardiologist and the broncopneumologist. A nutrition specialist should be consulted for feeding problems. The surviving patients will benefit from physical therapy, which should start in the first months of life in babies manifesting hypotonia/ hypertonia and motor delays. In the surviving patients, neuropsychological assessment should be performed every year to check for the presence of developmental and cognitive delay. Deficits should be treated with rehabilitative programs. The correction of SHFM depends on the individual anatomic defects, and should be managed by orthopaedics and plastic surgeons. When indicated, genital anomalies should be treated by surgeons or urologists.

\section{Prognosis}

Life expectancy is very poor in ACFS individuals. Most of the known patients survived only a few hours or months. Cardiopulmonary complications were the main cause of death. Two patients were alive at time of the observation, respectively at 4 and 25 years.

\section{Consent}

Written informed consent was obtained from the patients' parents for publication of these case reports and accompanying images. A copy of the written consent is available for review by the Editor-in Chief of this journal.

\section{Abbreviations}

ACFS: acro-cardio-facial syndrome; CCGE: cleft palate-cardiac defect-genital anomalies-ectrodactyly; CHD: congenital heart defect; EEC: ectrodactlyectodermal defect-clefting; OMIM: Online Mendelian Inheritance in Man; SHFM: split-hand/split-foot malformation. 


\section{Authors' contributions}

$M C D$ and $B D$ have revised the literature and drafted the manuscript. All authors have read and approved the final manuscript.

\section{Competing interests}

The authors declare that they have no competing interests.

Received: 17 April 2010 Accepted: 29 September 2010

Published: 29 September 2010

\section{References}

1. Richieri-Costa A, Orquizas LC: Ectrodactyly, cleft/lip palate, ventricular septal defect, micropenis and mental retardation in a Brazilian child born to consanguineous parents. Rev Brasil Genet 1987, 10:787-792.

2. Giannotti A, Digilio MC, Mingarelli R, Dallapiccola B: An autosomal recessive syndrome of cleft palate, cardiac defect, genital anomalies, and ectrodactyly (CCGE). J Med Genet 1995, 32:72-74.

3. Guion-Almeida ML, Zechi-Ceide RM, Richieri-Costa A: Cleft lip/palate, abnormal ears, ectrodactyly, congenital heart defect, and growth retardation: definition of the acro-cardio-facial syndrome. Clin Dysmorphol 2000, 9:269-272.

4. Mingarelli R, Zuccarello D, Digilio MC, Dallapiccola B: A new observation of acro-cardio-facial syndrome substantiates interindividual clinical variability. Am J Med Genet 2005, 136A:84-86.

5. Sivasli O, Ozer EA, Ozer A, Aydinlioglu H, Helvaci M: Acro-cardio-facial syndrome associated with neuoepithelial cyst: a case report. Genet Couns 2007, 18:247-250.

6. Kariminejad A, Bozorgmehr B, Sedighi Gilani MA, Almadani N, Kariminejad MH: Clinical variability in acro-cardio-facial syndrome. Am J Med Genet 2008, 146A:1977-1979.

7. Tanpaiboon P, Sittiwangkul R, Dejkhamron P, Srikummool M, Sripathomsawat W, Kantaputra P: Expanding the phenotypic spectrum of acro-cardio-facial syndrme (ACFS): exclusion of p63 mutation. Am J Med Genet 2009, 149A:1749-1753.

8. Celli J, Duijf P, Hamel BCJ, Barmshad M, Kramer B, Smits AP, NewburyEcob R, Hennekam RCM, van Buggenhout G, van Hearingen A, Woods CG, van Essen AJ, de Waal R, Vriend G, Haber DA, Yang A, McKeon F, Brunner $\mathrm{HG}$, van Bokhoven $\mathrm{H}$ : Heterozygous germline mutations in the p53 homolog p63 are the cause of EEC syndrome. Cell 1999, 99:143-153.

9. Rodini ESO, Richieri-Costa A: EEC syndrome: report on 20 new patients, clinical and genetic considerations. Am J Med Genet 1990, 37:42-.

10. Rapp RS, Hodgkin WE: Anhidrotic ectodermal dysplasia: autosomal dominant inheritance with palate and lip anomalies. J Med Genet 1968, 5:269-272.

11. Rosselli D, Giulienetti R: Ectodermal dysplasia. Br J Plast Surg 1961, 14:190-240.

12. Bowen $\mathrm{P}$, Amstrong HB: Ectodermal dysplasia, mental retardation, cleft lip/palate and other anomalies in three sibs. Clin Genet 1976, 9:35-42.

13. Malpuech G, Demeocq F, Palcoux JB: A previously undescribed autosomal recessive multiple congenital anomalies/mental retardation (MCA/MR) syndrome with growth failure, lip/palate cleft(s), and urogenital anomalies. Am J Med Genet 1983, 16:475-480.

14. Greenberg F, Gresik MV, Carpenter RJ, Law SW, Hoffman LP, Ledbetter DH: The Gardner-Silengo-Wachtel or genito-palato-cardiac syndrome: male pseudoermaphroditism with micrognathia, cleft palate, and conotruncal cardiac defect. Am J Med Genet 1987, 26:59-64.

doi:10.1186/1750-1172-5-25

Cite this article as: Digilio and Dallapiccola: Acro-cardio-facial syndrome. Orphanet Journal of Rare Diseases 2010 5:25.

\section{Submit your next manuscript to BioMed Central and take full advantage of:}

- Convenient online submission

- Thorough peer review

- No space constraints or color figure charges

- Immediate publication on acceptance

- Inclusion in PubMed, CAS, Scopus and Google Scholar

- Research which is freely available for redistribution

Submit your manuscript at www.biomedcentral com/submit
Biomed Central 